\title{
Starch-g-poly(benzyl methacrylate) copolymers
}

\author{
Characterization and thermal properties
}

\author{
Marta Worzakowska ${ }^{1}$
}

Received: 27 October 2015/ Accepted: 3 February 2016/Published online: 18 February 2016

(c) The Author(s) 2016. This article is published with open access at Springerlink.com

\begin{abstract}
The physicochemical properties such as swelling in polar and non-polar solvents, moisture resistance, chemical resistance, ability for gelatinization and the thermal properties along with the evolution of volatile decomposition products of some starch-g-copolymers obtained through the grafting of benzyl methacrylate monomer onto potato starch have been studied. The chemical structure of copolymers was confirmed using ATR-FTIR analysis. The prepared materials were characterized by completely different properties than unmodified potato starch due to the covalent bonding of poly(benzyl methacrylate) chains onto starch backbone. The copolymers were not able to gelate; however, they exhibited higher swelling in non-polar solvents, lower swelling in polar solvents and higher resistance toward moisture, acid and base conditions than unmodified potato starch. In addition, DSC analysis showed that $T_{\mathrm{g}}$ of copolymers was shifted to a little higher values as compared to $T_{\mathrm{g}}$ of poly(benzyl methacrylate). The thermal stabilities of copolymers and potato starch were comparable. Their decomposition took place in two main stages connected with the emission of various volatile decomposition products $\left(\mathrm{CO}_{2}, \mathrm{CO}, \mathrm{H}_{2} \mathrm{O}, \mathrm{CH}_{4}\right.$, aldehydes, alcohols, furan derivatives, acids, benzyl methacrylate) in inert atmosphere as it was confirmed based on the simultaneous TG/DSC/ FTIR analysis.
\end{abstract}

Marta Worzakowska

marta.worzakowska@poczta.umcs.lublin.pl

1 Department of Polymer Chemistry, Faculty of Chemistry, Maria Curie-Skłodowska University, Gliniana 33 Street, 20-614 Lublin, Poland
Keywords Potato starch - Graft copolymerization . Thermal properties · Physicochemical properties . TG/DSC/FTIR

\section{Introduction}

The modification of biopolymers is one of the most active fields of research which allows preparing novel, cheap and more environmentally friendly materials based on renewable resources. Among biopolymers, polysaccharides such as starch, cellulose, xyloglucans, pectins and chitosan are of great industrial and academic interest as materials suitable for the physical, enzymatic and chemical modification due to their valuable properties such as low cost, availability, nontoxicity, low environmental pollution or renewability [1-15].

Starch is one of the most abundant biomass materials produced by many green plants, natural energy source in the human diet and widely used polysaccharide in diverse areas of industry such as food, textile, paper, pharmaceutical, cosmetic or plastic. Non-modified starch is a hydrophilic biopolymer, granular in form, insoluble in cold water which gelatinizes in hot water. Starch is low resistance polymer toward acidic and moisture environment and it is characterized by low flowability, amorphous swelling, incompatibility with hydrophobic polymers and poor processability which have considerable influence on the limiting it practical applications [11-13]. According to the literature survey, in last years, many researches and industrials have studied the chemical starch modification processes, their influence on the properties and potential, practical utilization of modified starch-based materials. The properties of starch can be modified in different ways such as oxidation, esterification, etherification, hydrolysis, cross-linking and grafting [16-20] in order to increase its 
thermal stability, acid or moisture resistance, change the texture, viscosity, adhesion, etc. Among them, grafting of vinyl monomers onto polysaccharide backbone is a convenient method which allows improving poor properties of polysaccharides or creating materials which are characterized by new physical or chemical properties. Generally, the grafting process of hydrophilic or hydrophobic vinyl monomers onto carbohydrate polymers backbone allows creating more biocompatible and more environmentally friendly polymeric materials as compared to petroleumbased polymers. The hydrophobic starch graft modification has resulted in obtaining amphiphilic nature materials with a wide range of applications such as adsorbents, stabilizers, modifiers, compatibilizers, fillers, matrices, matrix or excipients for the drug delivery systems or plastics [21-26]. Many factors, e.g., temperature, time, initiator type, ratio of carbohydrate polymer to a vinyl monomer, have important influence on the course of the grafting. Due to this, suitable choice of the reaction parameters is essential to obtain the materials with high grafting percent and thus with more modified and improved properties as compared to native polysaccharides [21-26].

The present paper focuses on the physicochemical and thermal properties of some starch-g-copolymers obtained under grafting process of benzyl methacrylate monomer onto potato starch backbone. The grafting process was carried out in optimum temperature and time conditions $\left(80{ }^{\circ} \mathrm{C}, 2 \mathrm{~h}\right)$ and different starch-to-monomer ratio in the presence of potassium persulfate as a radical initiator. The effect of grafting percent on the swelling properties, moisture and chemical resistance, gelatinization properties, glass transition temperature, thermal stability, thermal decomposition pathways and the type of volatile decomposition products emitted under heating of copolymers in inert conditions has been evaluated.

\section{Experimental}

\section{Materials}

Potato starch was isolated from potato flour (Melvit S.A., Poland) according to the procedure described in Ref. [27]. The benzyl methacrylate monomer $(99 \%)$ was obtained from Sigma-Aldrich. Potassium persulfate, methanol, chloroform and tetrahydrofuran were delivered by Merck, Germany.

\section{Synthesis of starch-g-copolymers}

The copolymerization process of potato starch and benzyl methacrylate monomer was carried out in a three necked glass flask $\left(100 \mathrm{~cm}^{3}\right)$ equipped with a mechanical stirrer, a thermometer and a nitrogen gas inlet. The $2.5 \mathrm{~g}$ of potato starch and $50 \mathrm{~cm}^{3}$ of distilled water were heated at $80{ }^{\circ} \mathrm{C}$ for $30 \mathrm{~min}$. Then, the flask was purred with nitrogen and $1.0 \%$ of potassium persulfate was added and stirred at $80{ }^{\circ} \mathrm{C}$ for the next $30 \mathrm{~min}$. Finally, to the flask, benzyl methacrylate monomer in one portion was added and stirred (300 rmp) at $80{ }^{\circ} \mathrm{C}$ under nitrogen for the next $2 \mathrm{~h}$. The grafting process was performed with potato starch-to-monomer ratio of 1:0.75, 1:1, 1:1.25, 1:1.5 and $1: 2$. After the reaction was complete, the flask content was poured over to methanol $\left(100 \mathrm{~cm}^{3}\right)$. The precipitate was filtered and dried in an oven to a constant mass. The homopolymer was separated by Soxhlet extraction using chloroform and tetrahydrofuran as solvents. The purified copolymers were washed with methanol and dried to a constant mass at $60{ }^{\circ} \mathrm{C}$ [28]. The grafting parameters such as the grafting efficiency $(\mathrm{GE} / \%)$ and the grafting percent $(\mathrm{G} / \%)$ were evaluated using the following equations according [29, 30]:

$$
\begin{aligned}
\mathrm{GE} / \%= & \frac{\text { Mass of grafted polymer }}{\text { Mass of grafted polymer }+ \text { Mass of homopolymer }} \\
& \times 100
\end{aligned}
$$

$\mathrm{GE} / \%=\frac{\text { Mass of polymer grafted }}{\text { Mass of starch }} \times 100$.

\section{Characterization of starch-g-copolymers}

ATR-FTIR spectra were determined on a Tensor 27, Bruker, Germany Fourier transform infrared (FTIR) spectrometer equipped with a diamond crystal. Sixty-four scans over the $600-4000 \mathrm{~cm}^{-1}$ wavenumber region and a resolution of $4 \mathrm{~cm}^{-1}$ were collected.

The swelling studies of copolymers in polar and nonpolar solvents at $25{ }^{\circ} \mathrm{C}$ were investigated. The swellability coefficients $(B)$ were determined by equilibrium swelling of copolymers at $25{ }^{\circ} \mathrm{C}$ and calculated according to the following equation [31]:

$B=\frac{V_{\mathrm{s}}-V_{\mathrm{d}}}{V_{\mathrm{d}}} \times 100$

where $V_{\mathrm{s}}$ is the volume of the copolymer after swelling and $V_{\mathrm{d}}$ is the volume of the dried copolymer.

Moisture resistance studies were performed in an exsiccator. In a typical procedure, ca. $100 \mathrm{mg}$ of obtained copolymers were placed in an exsiccator and exposed to the water vapor at $25{ }^{\circ} \mathrm{C}$ for $24 \mathrm{~h}$. Percent moisture absorbance was calculated according to equation presented below [32]:

$M / \%=\frac{m_{\mathrm{e}}-m_{\mathrm{i}}}{m_{\mathrm{i}}} \times 100$ 
where $m_{\mathrm{e}}$ is the final mass of the sample and $m_{\mathrm{i}}$ is the initial mass of the sample.

The chemical resistance studies were conducted against hydrochloric acid $(1 \mathrm{M})$ and sodium hydroxide $(1 \mathrm{M})$. The ca. $100 \mathrm{mg}$ of potato starch or copolymers were treated with $\mathrm{HCl}$ or $\mathrm{NaOH}$ until a constant mass of the sample was reached. Then, the samples were filtered, carefully washed with distilled water to neutrality and dried at $60{ }^{\circ} \mathrm{C}$ to a constant mass. The chemical resistance was calculated according to the Eq. 5 [33]:

$\mathrm{WL} / \%=\frac{m_{1}-m_{2}}{m_{1}} \times 100$

where $m_{1}$ is the initial mass of the sample and $m_{2}$ is the final mass of the sample.

The glass transition temperature $\left(T_{\mathrm{g}}\right)$ and gelatinization temperature of the studied materials were evaluated by using a DSC 204 Jupiter F1 instrument, NETZSCH, Germany. The analyses were carried out in closed $\mathrm{Al}$ crucibles in inert atmosphere (argon, $40 \mathrm{~cm}^{3} \mathrm{~min}^{-1}$ ) with a heating rate of $10{ }^{\circ} \mathrm{C} \mathrm{min}^{-1}$ in the temperature range of $20-100{ }^{\circ} \mathrm{C}$ (the gelatinization properties) or $25-150{ }^{\circ} \mathrm{C}\left(T_{\mathrm{g}}\right)$. In order to evaluate the gelatinization properties, ca. $3 \mathrm{mg}$ of starchg-copolymers and ca. $6 \mathrm{mg}$ of distilled water in crucible were placed. The crucibles were put away for $24 \mathrm{~h}$ at room temperature to equilibrate and then tested.

The thermal properties of obtained copolymers were determined on a simultaneous thermal analyzer STA 449 Jupiter F1, NETZSCH, Germany instrument. The ca. $10 \mathrm{mg}$ of the sample was heated from 40 up to $740{ }^{\circ} \mathrm{C}$ with a heating rate of $10{ }^{\circ} \mathrm{C} \mathrm{min}{ }^{-1}$ under inert conditions (nitrogen, purge flow $40 \mathrm{~cm}^{3} \mathrm{~min}^{-1}$ ). The analyses were done in open $\mathrm{Al}_{2} \mathrm{O}_{3}$ crucibles.

The identification of volatile decomposition products created under heating of the copolymers was done by using an FTIR spectrometer TGA 585 Bruker, Germany coupled online to a STA instrument by a Teflon transfer line. The gas FTIR spectra were recorded from 600 to $4000 \mathrm{~cm}^{-1}$.

\section{Results and discussion}

\section{Characterization of starch-g-copolymers}

The starch-g-poly(benzyl methacrylate) copolymers were obtained under free-radical copolymerization of different potato starch-to-benzyl methacrylate ratio, Table 1 . The preliminary studies have indicated that the temperature of $80{ }^{\circ} \mathrm{C}$ and reaction time of $2 \mathrm{~h}$ were optimal parameters in order to prepare the copolymers with high grafting percent. Therefore, in this report, only the results obtained for optimal conditions have been presented. As it is clearly
Table 1 Potato starch-to-monomer ratio and the resulting grafting parameters ( $\mathrm{GE}$ and $G$ ) of the copolymerization process

\begin{tabular}{llll}
\hline Sample & $\begin{array}{l}\text { Starch-to-monomer } \\
\text { ratio }\end{array}$ & GE/\% & G/\% \\
\hline Copolymer 1 & $1: 0.75$ & $71.7 \pm 0.2$ & $33.1 \pm 0.5$ \\
Copolymer 2 & $1: 1$ & $74.2 \pm 0.3$ & $40.2 \pm 0.7$ \\
Copolymer 3 & $1: 1.25$ & $75.8 \pm 0.4$ & $53.4 \pm 0.3$ \\
Copolymer 4 & $1: 1.5$ & $65.4 \pm 0.4$ & $47.2 \pm 0.4$ \\
Copolymer 5 & $1: 2$ & $53.0 \pm 0.3$ & $43.3 \pm 0.6$ \\
\hline
\end{tabular}

visible, the grafting parameters change as the starch-tomonomer ratio changes. The grafting efficiency and grafting percent increase with the increasing starch-tomonomer ratio from 1:0.75 up to 1:1.25. Then, the grafting parameters decreased. The copolymers show the values of GE range from $53 \% \pm 0.3$ to $75.8 \% \pm 0.4$. The maximum of grafting parameters ( $G$ and GE) was obtained for starch-to-monomer ratio of $1: 1.25$. It confirmed that this composition is optimal in order to obtain copolymers with the highest grafting percent $(G)$ under the applied synthesis conditions.

Figure 1 shows the ATR-FTIR spectra of the copolymer (G $53.4 \% \pm 0.3$ ), potato starch and poly(benzyl methacrylate) in order to compare the results. The differences between starch FTIR spectrum and the FTIR spectra of copolymers are clearly observed. FTIR spectrum of starch shows the characteristic bands corresponding to the stretching vibrations of $\mathrm{OH}$ groups (the region of $3000-3600 \mathrm{~cm}^{-1}$ ), the stretching vibrations of $\mathrm{C}-\mathrm{H}$ (at $2840-2930 \mathrm{~cm}^{-1}$ ), the stretching vibrations of $\mathrm{C}-\mathrm{O}-\mathrm{H}$ and the $\mathrm{C}-\mathrm{O}-\mathrm{C}$ (the region of $998-1150 \mathrm{~cm}^{-1}$ ) [34, 35]. However, on the FTIR spectra of copolymers the appearance of additional bands is indicated. The bands which range from 3030 to $3070 \mathrm{~cm}^{-1}$ are due to the stretching vibrations of $\mathrm{C}_{\mathrm{Ar}}-\mathrm{H}$. The peak at $1722 \mathrm{~cm}^{-1}$ is assigned to the stretching vibrations of the carbonyl groups in esters. The bands centered at $695,745,1450-1480 \mathrm{~cm}^{-1}$ are characteristic for the out-of-plane ring deformation vibrations of $\mathrm{C}_{\mathrm{Ar}-\mathrm{H}}$ and the stretching vibrations of $\mathrm{C}=\mathrm{C}$ at the phenyl ring, respectively. The stretching vibrations (sym and asym) of C-O of starch and graft polymer between 997 and $1256 \mathrm{~cm}^{-1}$, Table 2 are observed [35]. It demonstrates the differences in the structure of starch and copolymers and confirms that the grafting process between benzyl methacrylate monomer and gelatinized potato starch was successful and allowed obtaining the novel polymeric materials.

All the prepared starch-g-poly(benzyl methacrylate) copolymers are in the form of white powders which are insoluble in polar and non-polar solvents. However, the swelling of copolymers in both type of solvents is clearly observed, Table 3. What is interesting is that the swelling 
Fig. 1 FTIR spectra of potato starch (a), starch-g-copolymer with $G=53.4 \% \pm 0.3(b)$ and poly(benzyl methacrylate) $(c)$

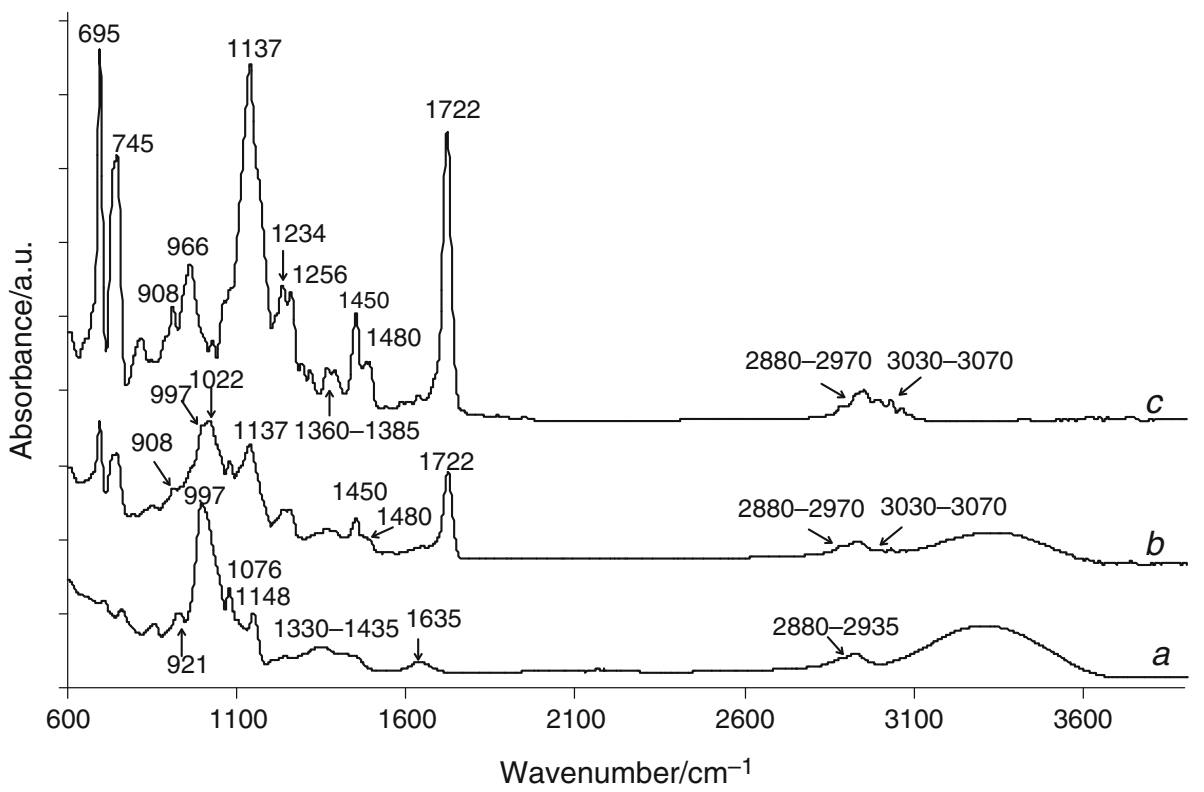

Table 2 FTIR assignment of homopolymer, starch-g-copolymers and potato starch

\begin{tabular}{|c|c|}
\hline Wavenumber $/ \mathrm{cm}^{-1}$ & Assignment \\
\hline \multicolumn{2}{|l|}{ Homopolymer } \\
\hline $3030-3070$ & $\mathrm{C}_{\mathrm{Ar}}-\mathrm{H}$ stretching \\
\hline 2880-2970 & $\mathrm{C}-\mathrm{H}$ stretching \\
\hline 1722 & $\mathrm{C}=\mathrm{O}$ stretching \\
\hline $1450-1480$ & $\mathrm{C}=\mathrm{C}_{\mathrm{Ar}}$ stretching \\
\hline $1360-1385$ & $\mathrm{C}-\mathrm{H}$ deformation \\
\hline $966-1256$ & $\mathrm{C}-\mathrm{O}$ stretching \\
\hline 840-908 & $\mathrm{C}-\mathrm{C}$ skeletal \\
\hline 695,745 & $\mathrm{C}_{\mathrm{Ar}}-\mathrm{H}$ out-of-plane deformation \\
\hline \multicolumn{2}{|l|}{ Starch-g-copolymer } \\
\hline $3000-3600$ & $\mathrm{O}-\mathrm{H}$ stretching \\
\hline $3030-3070$ & $\mathrm{C}_{\mathrm{Ar}}-\mathrm{H}$ stretching \\
\hline 2880-2970 & $\mathrm{C}-\mathrm{H}$ stretching \\
\hline 1722 & $\mathrm{C}=\mathrm{O}$ stretching \\
\hline 1635 & $\mathrm{O}-\mathrm{H}$ bending of absorbed water \\
\hline $1450-1480$ & $\mathrm{C}=\mathrm{C}_{\mathrm{Ar}}$ stretching \\
\hline 1360-1385 & $\mathrm{C}-\mathrm{H}$ deformation \\
\hline 997-1256 & $\mathrm{C}-\mathrm{O}$ stretching \\
\hline 695,745 & $\mathrm{C}_{\mathrm{Ar}}-\mathrm{H}$ out-of-plane deformation \\
\hline \multicolumn{2}{|l|}{ Potato starch } \\
\hline $3000-3600$ & $\mathrm{O}-\mathrm{H}$ stretching \\
\hline 2880-2935 & $\mathrm{C}-\mathrm{H}$ stretching \\
\hline 1635 & $\mathrm{O}-\mathrm{H}$ bending of absorbed water \\
\hline $1330-1345$ & $\mathrm{C}-\mathrm{H}$ deformation \\
\hline $921-1148$ & $\mathrm{C}-\mathrm{O}$ stretching \\
\hline
\end{tabular}

of copolymers is considerably lower in polar solvents as compared to the swelling of potato starch. Meanwhile, it can be certified that their swelling depends on the grafting percent. As a consequence of the presence of the apolar benzyl methacrylate, the swellability coefficients in polar solvents decrease with increasing grafting percent as is given in Table 3. However, the behavior of copolymers in non-polar solvents is completely different. As the grafting percent increases, better solvolysis of copolymers by nonpolar solvents and their higher swelling than potato starch is observed [28]. Based on those data, it can be concluded that the hydrophilic interactions between copolymers and polar solvents are stronger for copolymers which are characterized by lower $G / \%$. On the contrary, the hydrophobic interactions between copolymer and non-polar solvents are stronger for copolymers with higher $G / \%$.

Table 4 shows the results of the moisture absorbance studies. As it is clearly visible, the covalent bonding of poly(benzyl methacrylate) chains onto starch backbone causes obtaining less sensitive copolymers toward moisture. In addition, it was confirmed that as the grafting percent $(G)$ of copolymers is increased, the copolymers are more moisture resisted as compared to copolymers with lower $G$ and potato starch. DSC technique was applied to study the gelatinization properties of prepared copolymers. Based on the performed studies, the gelatinization of copolymers was not observed. The lack of the endothermic DSC signals responsible for the gelatinization properties of the studied materials was indicated. 
Table 3 Swellability coefficients $(B)$ of copolymers and potato starch* [28] in polar and non-polar solvents

\begin{tabular}{|c|c|c|c|c|c|c|}
\hline Sample & Water & Ethanol & Butanol & Toluene & $\mathrm{CCl}_{4}$ & Hexane \\
\hline Copolymer 1 & $35 \pm 2$ & $30 \pm 1$ & $25 \pm 2$ & $15 \pm 1$ & $17 \pm 2$ & $17 \pm 2$ \\
\hline Copolymer 2 & $30 \pm 1$ & $25 \pm 1$ & $20 \pm 1$ & $16 \pm 1$ & $17 \pm 1$ & $18 \pm 2$ \\
\hline Copolymer 3 & $25 \pm 2$ & $20 \pm 2$ & $18 \pm 2$ & $20 \pm 2$ & $20 \pm 1$ & $22 \pm 1$ \\
\hline Copolymer 4 & $25 \pm 2$ & $20 \pm 1$ & $17 \pm 3$ & $18 \pm 1$ & $19 \pm 2$ & $20 \pm 1$ \\
\hline Copolymer 5 & $27 \pm 1$ & $22 \pm 1$ & $18 \pm 2$ & $18 \pm 2$ & $18 \pm 1$ & $18 \pm 1$ \\
\hline Potato starch* & $70 \pm 3$ & $55 \pm 4$ & $39 \pm 2$ & $5 \pm 1$ & $8 \pm 1$ & $9 \pm 1$ \\
\hline
\end{tabular}

* Results for potato starch

Table 4 Percent moisture absorbance $(M)$ of copolymers and potato starch* [28]

\begin{tabular}{ll}
\hline Sample & $M / \%$ \\
\hline Copolymer 1 & $28.5 \pm 0.5$ \\
Copolymer 2 & $22.4 \pm 0.3$ \\
Copolymer 3 & $18.5 \pm 0.3$ \\
Copolymer 4 & $19.2 \pm 0.3$ \\
Copolymer 5 & $20.8 \pm 0.6$ \\
Potato starch* & $50.3 \pm 0.8$ \\
\hline
\end{tabular}

* Results for potato starch

Table 5 Chemical resistance of copolymers and potato starch* [28]

\begin{tabular}{lll}
\hline Sample & \multicolumn{2}{l}{ WL/\% } \\
\cline { 2 - 3 } & $1 \mathrm{M} \mathrm{NaOH}$ & $1 \mathrm{M} \mathrm{HCl}$ \\
\hline Copolymer 1 & $67.2 \pm 0.7$ & $42.2 \pm 0.4$ \\
Copolymer 2 & $56.9 \pm 0.6$ & $36.5 \pm 0.3$ \\
Copolymer 3 & $45.2 \pm 0.8$ & $22.3 \pm 0.8$ \\
Copolymer 4 & $50.5 \pm 0.3$ & $21.8 \pm 0.7$ \\
Copolymer 5 & $55.2 \pm 0.9$ & $20.5 \pm 0.5$ \\
Potato starch* & Gelatinized & $79.8 \pm 1.2$ \\
\hline
\end{tabular}

* Results for potato starch

Table 5 presents the results on the chemical resistance studies of starch-g-poly(benzyl methacrylate) copolymers and potato starch. Based on the presented data, potato starch gelatinized fully in alkaline conditions, which is in accordance with other studies [28, 36, 37]. However, the resistance of copolymers toward basic conditions is higher as compared to potato starch. What is interesting is that the base resistance of starch-g-poly(benzyl copolymers) is highly dependent on the grafting percent. As the grafting percent is increased, the copolymers are more stable in base conditions. Regarding my studies, the homopolymer formed under the grafting process is fully base resistant. On the other hand, the copolymers are characterized by higher resistance toward acidic conditions than starch. It is also clearly visible that their acid resistance is higher than their base resistance. In these studies, the mass loss of potato starch was ca. $80 \%$ in acidic conditions. Meanwhile, the mass loss of copolymers with grafting percent above $43 \%$ was only $20-22 \%$, Table 5 . It is concluded that the chemical modification of potato starch by the formation of poly(benzyl methacrylate) chains onto starch backbone caused obtaining the materials which are more resistant to chemical degradation process than potato starch.

\section{Thermal properties of copolymers}

The poly(benzyl methacrylate) obtained in this study is characterized by $T_{\mathrm{g}}$ value ca. $59{ }^{\circ} \mathrm{C}$, which is in accordance with the literature data $[38,39]$. It is worth noting that the $T_{\mathrm{g}}$ values of copolymers are shifted to little higher temperatures (ca. $65-67{ }^{\circ} \mathrm{C}$ ) as compared to the $T_{\mathrm{g}}$ of homopolymer, Fig. 2. It can be suspected that the covalent bonding of polymeric chains containing methyl, methylene and benzyl groups onto starch backbone caused the lower chain mobility of prepared materials, and thus, it allowed obtaining the copolymers which are characterized by more stiff structure.

TG/DTG/DSC curves of starch-g-copolymers gathered under inert atmosphere are shown in Fig. 3. The TG/DTG data are also given in Table 6. As it is clearly visible, the thermal properties of copolymers are very similar. Generally, at least three mass loss stages for starch-g-copolymers are appeared on the thermal curves. The first mass loss visible as a small DTG signal at temperatures lower than $150{ }^{\circ} \mathrm{C}$ with mass loss ca. $3-4 \%$ is connected with the evaporation of absorbed water by copolymers. However, the second and third mass loss stages which appear as nonwell separated signals on DTG curves are the result of the decomposition process of starch-g-poly(benzyl methacrylate) copolymers. The first decomposition stage for all studied copolymers spreads from ca. 240 up to $320-330{ }^{\circ} \mathrm{C}$ with comparable maximum mass loss temperature $\left(T_{\max 1}\right)$ values and mass loss ranges from 36 to $45 \%$, Table 6 . However, the second decomposition stage is visible from ca. 320-330 up to $550{ }^{\circ} \mathrm{C}$ with the maximum mass loss 
Fig. 2 DSC curves for copolymers and homopolymer: poly(benzyl methacrylate)

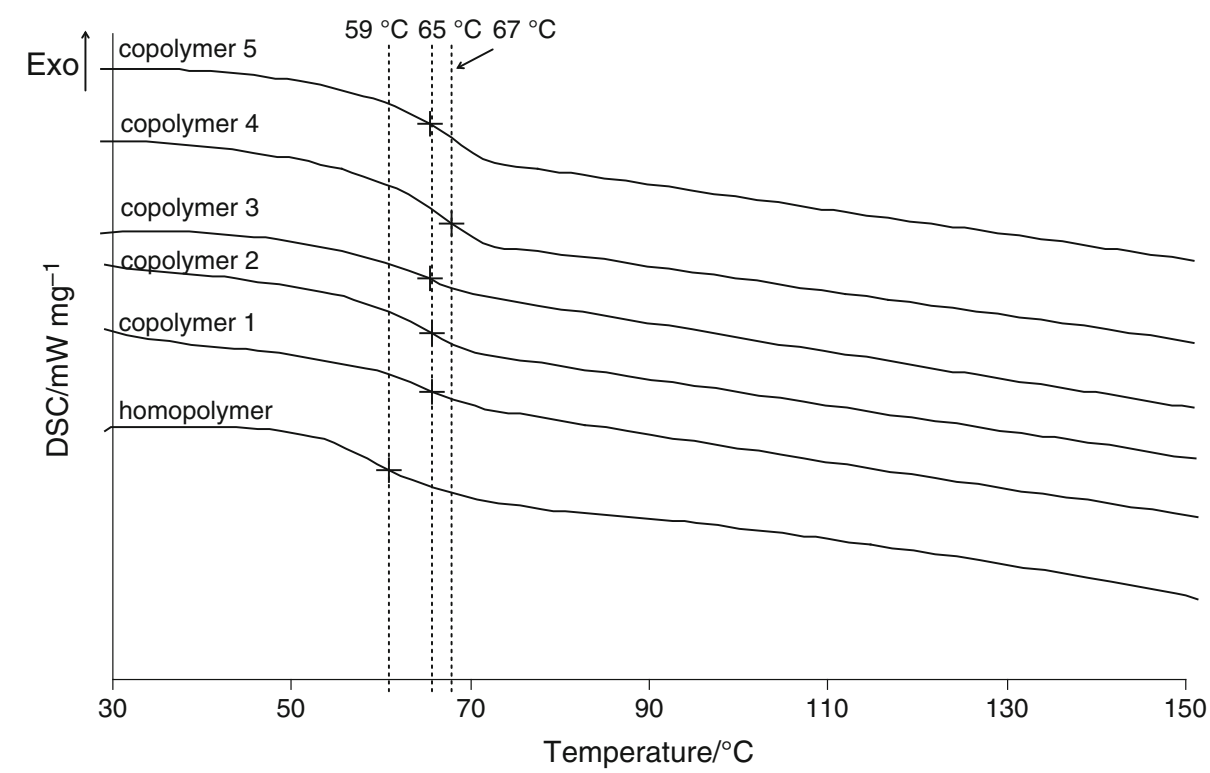

--- - copolymer 1

...... copolymer 2

- copolymer 3

-.--- copolymer 4

-.--copolymer 5

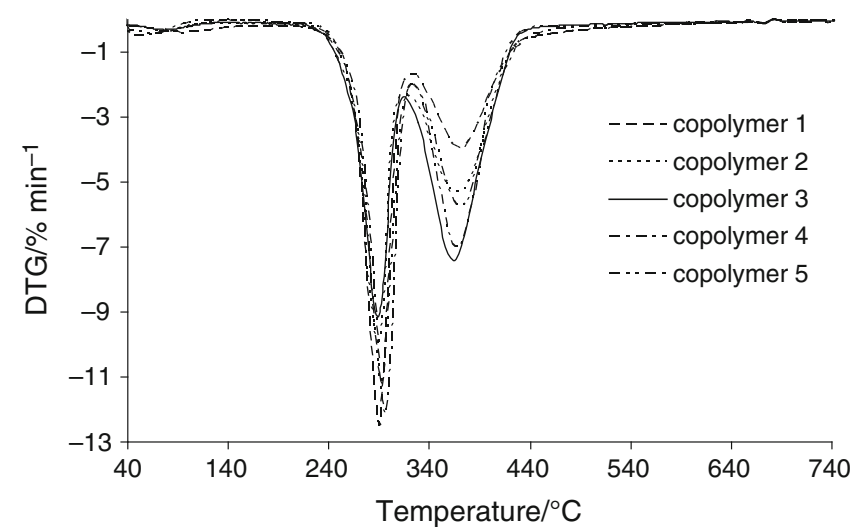

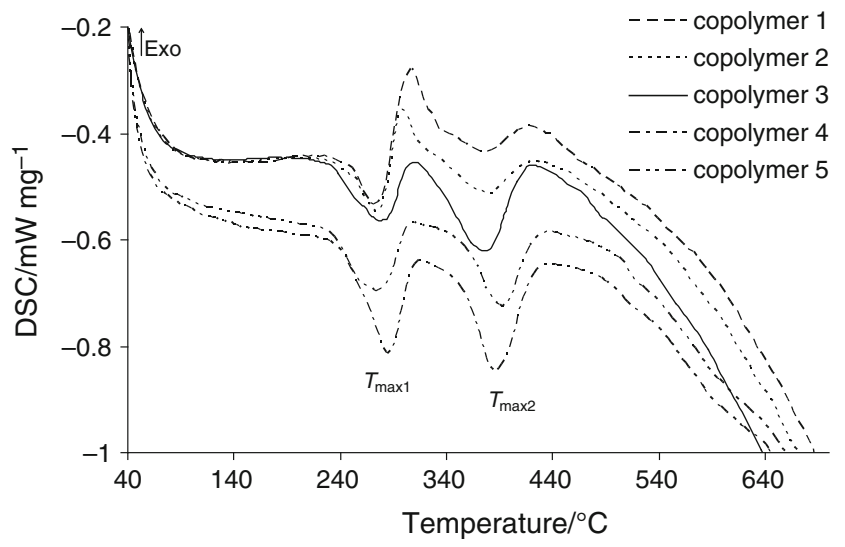

Fig. 3 TG/DTG/DSC curves of the starch-g-copolymers

temperature $\left(T_{\max 2}\right)$ from 366 to $375{ }^{\circ} \mathrm{C}$. It is worth noting that the mass loss in this stage is highly depended on the grafting percent. The degree of mass loss increased with increasing grafting percent at this temperature range. Their values hesitate from $28 \%$ for copolymer with the grafting percent of $33.1 \% \pm 0.5$ up to $48 \%$ for copolymer with 
Table 6 TG/DTG data of the studied starch-g-poly(benzyl methacrylate) copolymers

\begin{tabular}{|c|c|c|c|c|c|c|c|c|}
\hline Sample & $T_{\max 0} /{ }^{\circ} \mathrm{C}$ & $\Delta m_{0} / \%$ & $T_{\max 1} /{ }^{\circ} \mathrm{C}$ & $\Delta m_{1} / \%$ & $T_{\max 2} /{ }^{\circ} \mathrm{C}$ & $\Delta m_{2} / \%$ & $T_{\max 3} /{ }^{\circ} \mathrm{C}$ & $\Delta m_{3} / \%$ \\
\hline Copolymer 1 & 93 & 4 & 290 & 45 & 373 & 28 & - & 3 \\
\hline Copolymer 2 & 80 & 4 & 290 & 38 & 373 & 45 & - & 2 \\
\hline Copolymer 3 & 88 & 3 & 288 & 36 & 366 & 48 & - & 2 \\
\hline Copolymer 4 & 60 & 3 & 298 & 41 & 370 & 40 & - & 2 \\
\hline Copolymer 5 & 74 & 3 & 292 & 41 & 375 & 36 & - & 2 \\
\hline
\end{tabular}

Fig. 4 FTIR spectra of the gaseous products emitted during the decomposition of copolymer $1(\% G=33.1 \pm 0.5)$ and copolymer 3

$(\% G=53.4 \pm 0.3)$
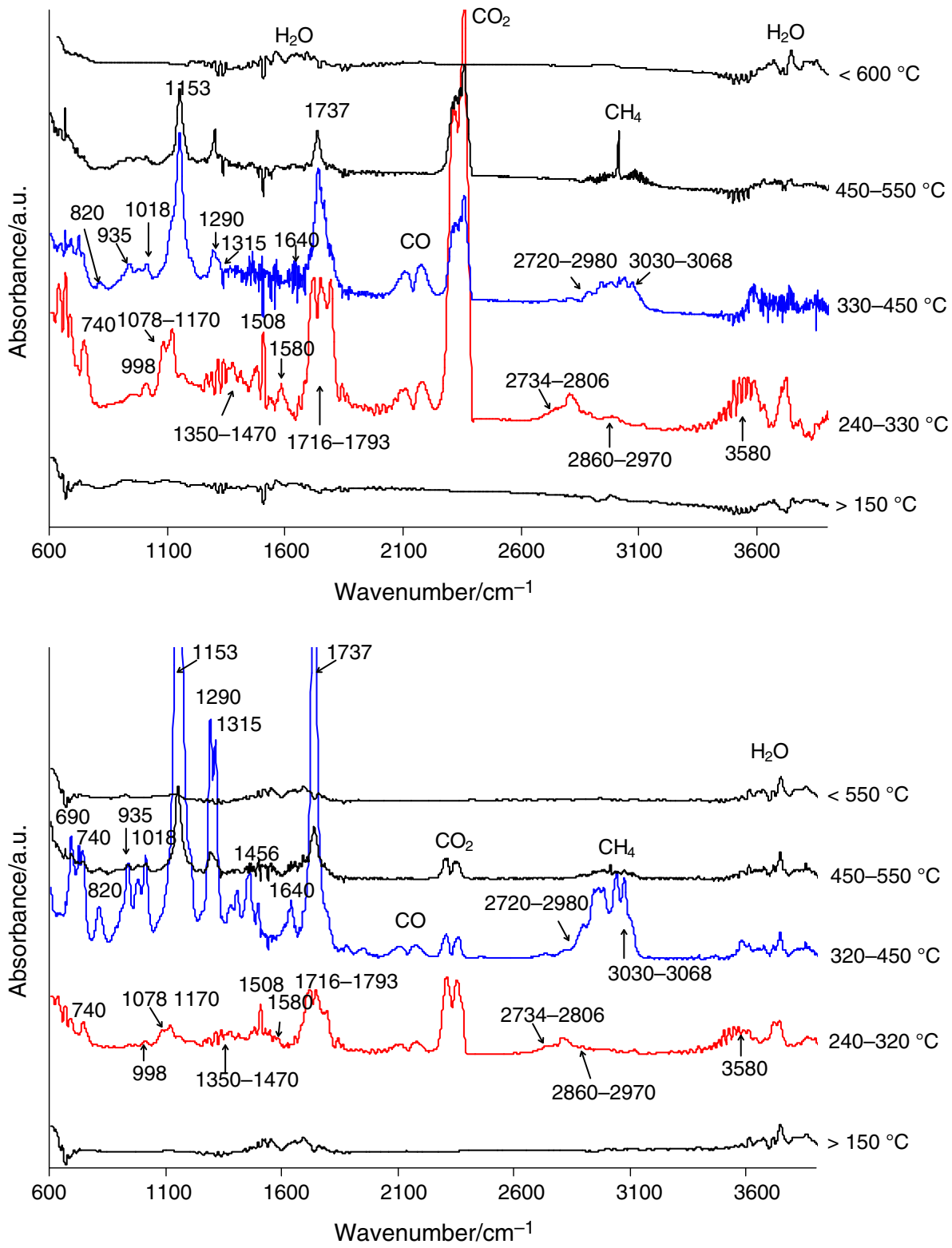

the grafting percent of $53.4 \% \pm 0.3$. Finally, at temperatures higher than $550{ }^{\circ} \mathrm{C}$, the small shoulder with the mass loss ca. 2-3\% on TG curves was observed. Correspondingly, on DSC curves two endothermic signals maximized at ca. $276-287{ }^{\circ} \mathrm{C}\left(T_{\max 1}\right)$ and at ca. $377-396{ }^{\circ} \mathrm{C}\left(T_{\max 2}\right)$ were observed. The appearance of the endothermic signals on DSC curves was directly connected with the main decomposition stages of the copolymers.

In order to evaluate the decomposition path of prepared copolymers, the FTIR analysis of the gaseous decomposition products emitted during heating of the materials in inert conditions was conducted. The example FTIR 
spectra gathered at different temperature range for two chosen copolymers are shown in Fig. 4. Due to the appearance of the same absorption signals on the FTIR spectra for copolymers $1-5$, only the FTIR spectra for copolymers which are characterized by minimum (copolymer 1) and maximum (copolymer 3) grafting percent are presented. The main differences between gaseous FTIR spectra for all studied copolymers were connected with the relative intensity of the emitted gaseous products, which were directly connected with the grafting percent, Fig. 4.

On the FTIR spectra gathered at temperature range where the first decomposition stage of copolymers is indicated, the absorption signals characteristic for the emission of $\mathrm{CO}_{2}$ (670 and $\left.2330-2365 \mathrm{~cm}^{-1}\right)$, $\mathrm{CO}$ $\left(2000-2200 \mathrm{~cm}^{-1}\right)$ and $\mathrm{H}_{2} \mathrm{O}\left(3500-3900 \mathrm{~cm}^{-1}\right)$ [40-43] are appeared. Besides those bands, the additional absorption signals connected with the evolution of other gaseous compounds are also identified. We can assume that the bands at $1716-1793 \mathrm{~cm}^{-1}$ (the stretching vibrations of $\mathrm{C}=\mathrm{O}$ ), at $2734-2806 \mathrm{~cm}^{-1}$ (the stretching vibrations of $\mathrm{C}-$ $\mathrm{H}$ in $\mathrm{O}=\mathrm{C}-\mathrm{H}$ groups), at $1078-1170 \mathrm{~cm}^{-1}$ (the stretching vibrations of $\mathrm{C}-\mathrm{O}$ ) and at $3580 \mathrm{~cm}^{-1}$ (stretching vibrations of $\mathrm{OH}$ ) are characteristic for the formation of aldehyde, alcohol and acid fragments. In addition, the presence of the signals at 2860-2970 $\mathrm{cm}^{-1}$ (the stretching vibrations of C$\mathrm{H}$ ), at $1350-1470 \mathrm{~cm}^{-1}$ (the deformation vibrations of $\mathrm{C}-$ $\mathrm{H}$ ) and at $740-998 \mathrm{~cm}^{-1}$ (out-of-plane deformation vibrations of the $\mathrm{C}-\mathrm{H}$ ) and at 1508 and at $1580 \mathrm{~cm}^{-1}$ (ring $\mathrm{C}=\mathrm{C}$ stretching vibrations) [43] may indicate on the creation of aliphatic and furan structures at these temperature range. The type of the emitted gaseous decomposition products indicates mainly on the breaking of the glycosidic bonds, strong bonds and thermal dehydration of starch from studied copolymers under the first decomposition stage. Those observations are in accordance with the results obtained by other researches [28, 40, 44-48].

However, as the temperature is higher than $320-330{ }^{\circ} \mathrm{C}$, among the emission of $\mathrm{CO}_{2}, \mathrm{CO}, \mathrm{H}_{2} \mathrm{O}$, one can observe the presence of the absorption bands characteristic for the evolution of benzyl methacrylate monomer. The FTIR spectra gathered under second decomposition stage of copolymers are in a good agreement with the gaseous FTIR spectra of benzyl methacrylate monomer tabulated in the NIST gaseous FTIR library spectra [43]. The results confirm that the main decomposition process of copolymers is connected with the depolymerization process of graft polymer chains [49]. However, as the temperature is higher than $450{ }^{\circ} \mathrm{C}$, the emission of $\mathrm{CH}_{4}\left(3014 \mathrm{~cm}^{-1}\right)$ among decomposition gases is indicated. It can be the result of secondary reactions which may happen at higher temperatures, e.g., reactions between chain radicals and carbonization of the residues.

\section{Conclusions}

The novel, amphiphilic starch-g-poly(benzyl methacrylate) copolymers were successfully prepared under free-radical copolymerization process of gelatinized potato starch and benzyl methacrylate monomer. As it was confirmed, those materials exhibited completely different properties than unmodified potato starch which was the result of the formation of poly(benzyl methacrylate) chains onto the starch backbone. Thus, the copolymers showed lower swelling in polar solvent but higher swelling in non-polar solvents, higher resistance toward moisture, higher resistance toward basic and acidic conditions than unmodified potato starch. The decomposition process of copolymers starts at temperatures ca. $240{ }^{\circ} \mathrm{C}$ and happens in two main stages. The first decomposition stage was mainly connected with the decomposition of starch from starch-g-copolymers. The second was due to the depolymerization process of the graft polymer. As a result, the emission of different gaseous products $\left(\mathrm{CO}_{2}, \mathrm{CO}, \mathrm{H}_{2} \mathrm{O}\right.$, aldehydes, alcohols, acids, furan derivatives, benzyl methacrylate and $\mathrm{CH}_{4}$ ) and the formation of char residues were indicated. Those results proved that by chemical modification of low cost, renewable and available potato starch by benzyl methacrylate monomer is possible to obtain novel, amphiphilic, more environmentally friendly materials which are promising materials such as fillers, stabilizers, modifiers, matrices or plastics which can replace non-biodegradable and compostable petroleum-based plastics materials.

Open Access This article is distributed under the terms of the Creative Commons Attribution 4.0 International License (http://crea tivecommons.org/licenses/by/4.0/), which permits unrestricted use, distribution, and reproduction in any medium, provided you give appropriate credit to the original author(s) and the source, provide a link to the Creative Commons license, and indicate if changes were made.

\section{References}

1. Mishra A, Malhotra AV. Graft copolymers of xyloglucan and methyl methacrylate. Carbohydr Polym. 2012;87:1899-904.

2. Roy D, Semsarilar M, Guthrie JT, Perrier S. Cellulose modification by polymer grafting: a review. Chem Soc Rev. 2008;38: 2046-64

3. Tessier R, Lafranche E, Krawczak P. Development of novel meltcompounded starch-grafted polypropylene/polypropylene-grafted maleic anhydride/organoclay ternary hybrids. eXPRESS Polym Lett. 2012;6:937-52.

4. Wang Z, Zhang Y, Jiang F, Fang H, Wang Z. Synthesis and characterization of designed cellulose-graft-polyisoprene copolymers. Polym Chem. 2014;5:3379-88.

5. Huang W, Wang Y, Zhang S, Huang L, Hua D, Zhu X. A facile approach for controlled modification of chitosan under $\gamma$-ray irradiation for drug delivery. Macromolecules. 2013;46:814-8. 
6. Tizzotti M, Creuzet C, Labeau M-P, Hamaide T, Boisson F, Drockenmuller E, Charlot A, Fleury E. Synthesis of temperature responsive biohybrid guar-based grafted copolymers by click chemistry. Macromolecules. 2010;43:6843-52.

7. Pal A, Das D, Kumar Sarkar A, Ghorai S, Das R, Pal S. Synthesis of glycogen and poly (acrylic acid)-based graft copolymers via ATRP and its application for selective removal of $\mathrm{Pb}^{2+}$ ions from aqueous solution. Eur Polym J. 2015;66:33-46.

8. Soledad Lencina MM, Ciolino AE, Andreucetti NA, Villar MA. Thermoresponsive hydrogels based on alginate- $g$-poly $(\mathrm{N}$-isopropylacrylamide) copolymers obtained by low doses of gamma radiation. Eur Polym J. 2015. doi:10.1016/j.eurpolymj.2015.03. 071.

9. Al-Sagheer FA, Ibrahim EI, Khalil KD. Crystallinity, antimicrobial activity and dyeing properties of chitosan-g-poly(Nacryloyl morpholine) copolymer. Eur Polym J. 2014;58:164-72.

10. Wang WB, Xu JX, Wang AQ. A pH-, salt- and solvent-responsive carboxymethylcellulose-g-poly(sodium acrylate)/medical stone superabsorbent composite with enhanced swelling and responsive properties. eXPRESS Polym Lett. 2011;5:385-400.

11. Ashok KS, Halley PJ. Starch modification to develop novel starchbiopolymer blends: state of art and perspectives. In: Halley PJ, Avérous LR, editors. Starch polymers: from genetic engineering to green applications. Burlington: Elsevier; 2014. p. 105-37.

12. Cui SW. Food carbohydrates: chemistry, physical properties, and applications. Boca Raton: Taylor \& Francis Group, CRC Press; 2005.

13. Costa Garcia M, Landi Franco CM, Soares Junior MS, Caliari M. Structural characteristics and gelatinization properties of sour cassava starch. J Therm Anal Calorim. 2015. doi:10.1007/ s10973-015-4990-5.

14. Mahanta AK, Mittal V, Singh N, Dash D, Malik S, Kumar M, Maiti P. Polyurethane-grafted chitosan as new biomaterials for controlled drug delivery. Macromolecules. 2015;48:2654-66.

15. Choi E-J, Kim CH, Park JK. Synthesis and characterization of starch-g-polycaprolactone copolymer. Macromolecules. 1999; 32:7402-8.

16. Gandini A. Polymers from renewable resources: a challenge for the future of macromolecular materials. Macromolecules. 2008;41:9491-504.

17. Hogbon AO, Akintayo ET. Recent trend in the physical and chemical modification of starches from different botanical sources: a review. Starch Stärke. 2014;66:41-57.

18. Xiao CM, Tan J, Xue GN. Synthesis and properties of starch-gpoly(maleic anhydride-co-vinyl acetate). eXPRESS Polym Lett. 2010;4:9-16.

19. Kolya H, Das S, Tripathy T. Synthesis of starch-g-poly-(Nmethylacrylamide-co-acrylic acid) and its application for the removal of mercury (II) from aqueous solution by adsorption. Eur Polym J. 2014;58:1-10.

20. Kolya H, Tripathym T. Hydroxyethyl starch-g-poly-(N, $\mathrm{N}$-dimethylacrylamide-co-acrylic acid): an efficient dye removing agent. Eur Polym J. 2013;49:4265-75.

21. Fanta GF, Burr RC, Doane WM, Russell CR. Graft polymerization of styrene onto starch by simultaneous cobalt-60 irradiation. J Appl Polym Sci. 1977;21:425-33.

22. Kaewtatip K, Tanrattanakul V. Preparation of cassava starch grafted with polystyrene by suspension polymerization. Carbohydr Polym. 2008;73:647-55.

23. Simi CK, Abraham TE. Hydrophobic grafted and crosslinked starch nanoparticles for drug delivery. Bioprocess Biosyst Eng. 2007;30:173-80.

24. Chujiang C, Jinzhi L, Zhigang S, Shulin M, Yushan X. Synthesis of hydrophobic corn starch with high flowability by surface modification. Starch Stärke. 2009;61:344-51.
25. Bravo-Osuna I, Ferrero C, Jiménez-Castellanos MR. Water sorption-desorption behaviour of methyl methacrylate-starch copolymers: effect of hydrophobic graft and drying method. Eur J Pharm Biopharm. 2005;59:537-48.

26. Liu Y, Li J, Yang L, Shi Z, Deng K. Graft copolymerization of methyl methacrylate onto starch using potassium ditelluratocuprate(III). J Macromol Sci Part A Pure Appl Chem. 2004;41:1025-35.

27. Lim ST, Lee JH, Shin DH, Lim HS. Comparison of protein extraction solutions for rice starch isolation and effects of residual protein content on starch pasting properties. Starch Stärke. 1999;51:120-5.

28. Worzakowska M, Grochowicz M. Effect of some parameters on the synthesis and the physico-chemical properties of new amphiphilic starch-g-copolymers. Carbohydr Polym. 2015;130:344-52.

29. Athawale VD, Rathi SC. Role and relevance of polarity and solubility of vinyl monomers in graft polymerization onto starch. React Funct Polym. 1997;34:11-7.

30. Fakhru'l-Razi A, Qudsieh IYM, Yunus WMZW, Ahmad MB, Rahman MZA. Graft copolymerization of methyl methacrylate onto sago starch using ceric ammonium nitrate and potassium persulfate as redox initiator system. J Appl Polym Sci. 2001;82:1375-81.

31. Tuncel K, Ecevit K, Kesenci Piskin E. Nonswellable and swellable ethylene glycol dimethacrylate-acrylic acid copolymer microspheres. J Polym Sci Part A Polym Chem. 1996;34:45-55.

32. Pathania D, Sharma R. Synthesis and characterization of graft copolymers of metyhacrylic acid onto gelatinized potato starch using chromic acid initiator in presence of air. Adv Mater Lett. 2012;3:136-42.

33. Kaith BS, Singha AS, Grupa SK. Graft copolymerization of flax fibres with binary vinyl monomer mixtures and evaluation of swelling, moisture absorbance and thermal behavior of the grafted fibres. J Polym Mater. 2003;20:195-9.

34. Demirelli K, Coskun M, Kaya E. Polymers based on benzyl methacrylate: synthesis via atom transfer radical polymerization, characterization and thermal stabilities. J Polym Sci Part A Polym Chem. 2004;42:5964-73.

35. Sokrates G. Infrared and Raman characteristic group frequencies, tables and charts. New York: Wiley; 2001.

36. Maher Peoria GG. Alkali gelatinization of starches. Starch Stärke. 1983;35:226-34.

37. Mangels CE, Bailey CH. Relation of concentration to action of gelatinizing agents on starch. J Am Chem Soc. 1933;55:1981-8.

38. Arribas C, Masegosa RM, Salom C, Arevalo E, Prolongo SG, Prolongo MG. Epoxy/poly(benzyl methacrylate) blends: miscibility, phase separation on curing and morphology. J Therm Anal Calorim. 2006;86:693-8.

39. Prolongo MG, Arribas C, Salom Rosa C, Masegosa M. Dynamic mechanical properties and morphology of poly(benzyl methacrylate)/epoxy thermoset blends. Polym Eng Sci. 2010;50: 1820-30.

40. Liu Z, Li W, Zhang Y, Wang J, Orndorff W, Pan WP. Influence of biomass on coal combustion based on thermogravimetry and Fourier transform infrared spectroscopy. J Therm Anal Calorim. 2015. doi:10.1007/s10973-015-4841-4.

41. Aburto J, Moran M, Galano A, Torres-García E. Non-isothermal pyrolysis of pectin: a thermochemical and kinetic approach. J Anal Appl Pyrolosis. 2015;112:94-104.

42. Tudorachi N, Mustafa F. Thermal degradation and evolved gas analysis of some vegetable oils using TG/FT-IR/MS technique. J Therm Anal Calorim. 2015;119:1703-11.

43. NIST Chemistry Webbook. NIST Standard Reference Data 2011. http://webbook.nist.gov. 
44. Simkovic I, Francis BA, Reeves JB. Pyrolysis-gas chromatography mass spectrometry analysis of starch-based ion-exchangers. J Anal Appl Pyrolysis. 1997;43:145-55.

45. Liu X, Wang Y, Yu L, Tong Z, Chen L, Liu H, Li X. Thermal degradation and stability of starch under different processing conditions. Starch Stärke. 2013;65:48-60.

46. Marques PT, Lima AMF, Bianko G, Laurindo JB, Borsali R, Le Meins JF, Soldi V. Thermal properties and stability of cassava starch films cross-linked with tetraethylene glycol diacrylate. Polym Degrad Stab. 2006;91:726-32.
47. Vasques CT, Domenech SC, Severgini VLS, Belmonte LAO, Soldi MS, Barretoc PLM. Effect of thermal treatment on the stability and structure of maize starch cast films. Starch Stärke. 2007;59:161-70.

48. Liu X, Yu L, Xie F, Li M, Chen L, Li X. Kinetics and mechanism of thermal decomposition of cornstarches with different amylose/ amylopectin ratios. Starch Stärke. 2010;62:139-46.

49. Itoh Y, Coshima T, Shirai H. Photolysis of poly(benzyl methacrylate)s and poly(benzyl acrylate)s in solution and films. J Appl Polym Sci. 2001;82:2227-36. 